\title{
Application of fuzzy probability in water quality management of a river system
}

\author{
K. Sasikumar $\dagger$ and P. P. MuJumdar $\dagger$
}

\begin{abstract}
Water quality management of a river system is addressed in $n$ fizzy and probabilistic framework. Two types of uncertainty, namely randomness and vagueness. ore treated simultaneously in the management problem. A fuzzy-set-based definition that is a more general case of the existing crisp-set-based definition of low water quality is introduced. The event of low water quality at a check-point in the river system is considered as a fuzzy event. The risk of low water qualify is then defined ar the probability of the fuzzy event of low' water quality. Instead of constraining the risk of violation of water quality standard by a finite value of risk through a chance constraint, afurry set of low risk that considers a range of risk levels with appropriate membership values is introduced. Different goals associated with rhr management problem are expressed as fuzzy sets. The resulting management problem is formulated as a fuzzy multiobjective optimization problem
\end{abstract}

\section{Introduction}

Water quality management of a river system is generally characterized by various types of uncertainty. One of the uncertainties that has received much attention is that due to randomness associated with various components of the river system. Two thajor components of the river system that grve rise lo randomness are the river Row and the effluent flow. These in turn make the water quality indices of interest random. The most common approach to incorporate the randomness of water quality indices in a management model is the adoption of a suitable probabilistic mathematical programming technique (see for example Lohari and Thanh (1978. 1979), Bum and McBean (1985), Fugiwara of al. (1986, 1987, 1988) and Ellis (1987)). Another lype of uncertainty that is as prominent as randomness and is little addressed in the area of water quality fnaragement Is vagueness associated with the description of the goals and the quantification of the low water quality. Incorporation of the uncertainty due 10 vagueness in engineering systems is achicved using the principles of

Received 3 November 1997 Revised 12 August 1998. Accepted 15 April 199\%

$\nmid$ Department of Civil Engineering. Indian Institute of Science, Bangalore-560 012. India fuzzy set theory (Zadeh 1965). Quantification of vagueness is made possible using the concepts of fuzzy sets and the associated membership functions. This is analogous to the quantification of randomness using the concepts of events and the associated probability density functions (PDFs). An uncertain system may be characterized hy the dominance of randomness or vagueness or both. A close look at the water quality management problem reveals that, for a river system. randomness is not the only relevant uncertainty but vagueness also may he of considerable importance. As a first instance, setting up the water quality criteria for any particular use of the water body may he painted out for the pres. ence of vagueness. A second instance is with the assignment of permissible risk levels for the violation of water quality standards. A management model that takes into account both randomness and vagueness may be expected to bo a more realistic decision-making tool for water quality mandgement of a river system. An atrempt is made in this panet to incorporate the two types of uncertainty, namely the randomness and vagueness, in a water quality management model for a river system

The management models that take the vagueness into account belong to the category of fuzzy optimization models. Fuzzy optimization models have been success- 
fully applied in the areas of structural optimization (Rao 1987 a, b, 1993, Rao et al. 1992) water quality management (Hathhorn and Tung 1989, Chang et af. 1997, Sasikumar and Mujumdar 1998), water resources allocation (Kindler 1992), hydroelectric generation scheduling (Liang and Hș 1994), reservoir operation (Fontane et al. 1997, Owen et al. 1997), and solid waste management (Chang and Wang 1996). Fuzzy optimization models make use of the concepts of fuzzy set theory (Zadeh 1965), fuzzy decision making (Bellman and Zadeh 1970) and fuzzy mathematical programming (Zimmermann 1978, 1985). Fuzzy optimization may be viewed as a multiobjective optimization technique in which the objectives are defined as fuzzy sets with appropriate membership functions. These membership functions play a key role in the management model. A few applications of fuzzy optimization in water quality management of a river system are briefly reviewed in the following paragraph.

Hathhorn and Tung (1989) addressed the waste load allocation process far water quality management of a river system in a fuzzy optimization framework. The two objectives considered in their study are maximization of the waste discharge and minimization of the largest difference in an equity measure between the various dischargers. These two objectives are expressed as fuzzy sets with either linear or logistic membership func tions. The multiobjective problem is then transformed into a fuzzy linestr programming problem with constraints due to water quality requirements, definition of largest difference in equity and the limitations on fraction removal levels. Chang et al. (1997) combined grey and fuzzy programming methods in an interactive multiobjective framework for water pollution control in a river basin. In their study, the uncertainty due to the environmental and economic parameters is modelled using interval numbers, and that due to the imprecise objectives identified by decision makers is modelled using fuzzy membership functions. The resulting interactive fuzzy interval multiobjective mixed integer programming approach is used to evaluate optimal wastewater treatment strategies for pollution control in a river basin. Sasikumar and Mujumdar (1998) developed a fuzzy waste load allocation model for water quality management of at river system in a deterministic framework. The model incorporates the conflicting objectives of the pollution control agency and dischargers in the system. The vagueness associated with setting up the water quality critertia and the aspirations of the pollution control agency and dischargers are quantified using fuzzy goals with appropritite membership functions. The management problem is formulated as a fuz7y multi. abjective optimization problem that can be solved using the linear programming technique. The work reported in this paper extends the model doveloped by
Sasikumar and Mujumdar (1998) by incorporating the uncertainty due to randomness together with the uncertainty due to vagueness.

Two important concepts for water quality management of a river system are considered in this paper The first concept is related to viewing the low water quality as a fuzzy event. The second concept is related to the definition of fuzzy risk for the violation of water quality standards. The risk of a low water quality event is derived using the concept of probability of a fuzzy event (Zadeh 1968). A water quality management model for a river system is developed in this paper incorporating these concepts. When the water quality indices at a check-point become random variables, the associated goals of the pollution control agency are modified by incorporating the probabilistic nature of the water quality indices. The goals of the pollution control agency are defined in terms of the risk of low water quality which is a fuzzy event. The objective of achieving low risk at a check-point is then expressed as a fuzzy set with appropriate membership functions. In order to make the model general, the goals related to the deterministic water quality indices at certain check-points are also telained in the model formulation. Far example, it may be possible to consider the water quality Indices deterministic at a some check-points due to a regulated flow from a reservoir with a fixed policy of operation. In general, the model identifies the goals of the pollution control agency and the aspirations of the dischargers as fuzzy sets. Appropriate membership functions are assigned to these fuzzy sets based on the nature of the goals and aspirations. The management problem is then formulated as a fuzzy multiobjective optimization problem. The Solution of the model yields optimum fraction removal levels for the pollutants in the river system. Section 2 of the paper deals with the mathematical treatment of the concepts of low water quality and low risk. The details of the management model is presented in section 3. Section 4 illustrates the application of the model to a hypothetical river syster. The river System considered for illustrating tite application of the management model is relatively simple for which the well-known Streeter-Phelps equations (Thomann and Mucller 1987) are used as the water quality model. Such an approach of using a simple water quality model is mainly to focus more on the iuzzy probabilistic aspect of the water quality management problem. However, a problem in which soptis. ticated water quality models are to be used may be formulated in a fuzzy probabilistic framework similat to that proposed in this paper. Sections 5 and 6 give the results and discussion respectively, and the imnort. ant conclusions drawn from the performance of the model. 


\section{Fuzzy description of low water quality}

\subsection{Description of the river system}

A general river system is used for describing the details of the fuzzy waste load allocation model. The river system consists of a set of dischargers who are allowed to release the pollutants into the river after removing some fraction of the pollutants. These fraction removal levels of the pollutants are necessary in order to maintain the acceptable water quality condition in the river as prescribed by the pollution control agency. A common practice of the pollution control agency to ensure the acceptable water quality condition is to check the water quality at a finite number of locations in the river. These locations are called water quality check-points or simply check-points. The water quality at a check-point is described by means of some indicators called water quality indices. The dissolved oxygen (DO deficit) is an example of a water quality index. The water quality indices may he of two kinds:

(I) indices whose desirable levels $\mathrm{n}$ the river are greater than the permissible levels (e.g. DO);

(2) indices whose desirable levels are less than the permissible levels (e.g. DO deficit and toxic pollutant concentration.

Most of the water quality indices are of kind (2). however. for the sake of generality, both kinds of water quality index are considered in the present study. The level of a water quality index at a checkpoint is affected by the controllable as well as the uncontrollable sources of pollutants in the river system. The level of the water quality index at a check-point is obtained using a water quality model that determines the spatial distribution of the pollutants in the river system. In a water quality management model. the level of the water quality index is expressed in terms of the fraction removal levels for the pollutants released hy the dischargers into the river system. These fraction remowal levels form the set ofdecision wariables in the optimization problem. The solution of the optimization problem gives the optimal fraction removal levels according to the objective function and consiraints considered in the problem formulation.

Table I gives the description of a river syston to which the model can he applied for water quality management. The relevant componers of the system are identified as sets. Set $Q_{t}$ represents the collection of Witer quality checkpoints in the river system. Set $D_{d i f}$ is the collection of dischargers (e.g. indusitjes). Set $P_{N}$ is the collection of the pollutants in the syslem (c.g. point sousces of brochemical oxygen demand (BOD). and a mixture of toxic substances). Set $T_{p}$ is the collection of uncontrollable sources of pollutants in the system (e.g.
BOD addition due to run-off and scour in a stream). Set $\mathrm{V}$, is the collection of water quality indices whose desirable levels are greater that the permissible levels for acceptable water quality (e.g. DO concentration). Set $S_{,}$is the collection of water quality indices whose desirable levels are less than the permissible levels for acceptable water quality (e.g. DO deficit and toxic pollutant concentration). The elements in the sets $V_{i}$ and $S_{j}$ are denoted by $i$ and $j$ respectively. A pollutant is assumed to affect one or more than one water quality index in the sets $V_{I}$ or $S_{J}$ or both. Note that no water quality index is common to sets $V_{I}$ and $S_{J}$. Concentration levels of the water quality indices $i$ and $j$ at the check-point $l$ are denoted as $c_{i l}$ and $c_{j l}$ respectively. The pollution control agency sets a desirable level $c_{i l}^{\mathrm{D}}$ and a minimum permissible level $c_{i l}^{\mathrm{L}}$ for the water quality index $i$ at the checkpoint $l\left(c_{i l}^{\mathrm{D}}>c_{i l}^{\mathrm{L}}\right)$. Similarly, $c_{j l}^{\mathrm{D}}$ and $c_{j l}^{\mathrm{H}}$ represent the desirable and maximum permissible levels respectively of the water quality index $j$ at the check-point $l$ $\left(c_{j l}^{\mathrm{D}}<c_{j l}^{\mathrm{H}}\right)$.

A common index $w$ is used for denoting the water quality indices $i$ as well as $j$ whenever no distinction is necessary between $i$ and $j$. This common index $w$ is used in order to avoid the repetition of formulae and other statements in which no distinction exists between $i$ and $j$. The equivalence of $w$ to $i$ and $j$ is indicated by the notation ' $w \Rightarrow i, j$ '. Whenever a discussion is relevant to any one of the indices $i$ or $j$, that index is explicitly stated.

\subsection{Low water quality as a fuzzy event}

The concepts related to the water quality and the associated risk are explained with reference to the water quality indices $i$ and $j$ (table I) whose concentrat. tions at a check-point $I$ in the river system are denoted as $c_{i l}$ and ${ }_{j}$. It may be noted that $c_{i r}$ denotes the concentration of the water quality index whose desirable level at the check-point $I$ is greater than the permissible level (e.g. DO concentration). Similarly, $c_{i j}$ corresponds to the water quality index whose desirable level is less than the permissible level (e.g. DO deficit and concentration of toxic substances). For $c_{i j}$, the conventional water quality criterion at the check-point $i$ is such that any concentration level of the water quality index less than a specified walue, say $c_{i l}^{\mathrm{L}}$ corresponds to a low water quality. In other words. a concentration level that is very close to but greater than $c_{i l}^{\mathrm{L}}$ is not considered to he a low water quality. This stringent definition of low water quutlity may be expressed mathematically using a characteristic function of $c_{i t}$ is $s$ follows:

$$
\mu\left(c_{i l}\right)= \begin{cases}1, & c_{i l}<c_{i l}^{\mathrm{L}}, \\ 0, & c_{i l} \geqslant c_{i l}^{\mathrm{L}} .\end{cases}
$$


Table 1. Description of the rives system.

\begin{tabular}{|c|c|c|c|}
\hline Set & $\begin{array}{l}\text { Description. } \\
\text { of the set. }\end{array}$ & $\begin{array}{l}\text { Element } \\
\text { representation }\end{array}$ & $\begin{array}{l}\text { Number } \\
\text { of elements }\end{array}$ \\
\hline $\begin{array}{l}Q_{L} \\
P_{M}^{M}\end{array}$ & $\begin{array}{l}\text { Water quality check-points } \\
\text { Dischargers } \\
\text { Pollutanis }\end{array}$ & $\begin{array}{l}l \\
m \\
n\end{array}$ & $\begin{array}{l}N_{Q} \\
N_{d} \\
5\end{array}$ \\
\hline $\begin{array}{l}T_{F} \\
V_{I} \\
S_{I}\end{array}$ & $\begin{array}{l}\text { Uacontrollable sources of pollutants } \\
\text { Wafer quality indices: desirable level > permissible level } \\
\text { Water quality indices: desirable level < permissible level }\end{array}$ & $\begin{array}{l}p \\
i \\
i\end{array}$ & $\begin{array}{l}N_{r} \\
N_{y} \\
N_{1}\end{array}$ \\
\hline
\end{tabular}

Similarly, for $c_{\%}$, the conventional water quality criterion is such that any concentration level of the water quality index greater than a specified value, say, $c_{f l}^{H}$, corresponds to a low water quality. In other words, a concentration level that is very close to but less than $c_{j l}^{\mathrm{H}}$ is not considered to be a low water quality. This definition may be expressed mathematically using a characteristic function of $c_{j l}$ as follows:

$$
\mu\left(c_{j l}\right)= \begin{cases}0, & c_{j l} \leqslant c_{j l}^{\mathrm{H}}, \\ 1, & c_{j l}>c_{j l}^{\mathrm{H}} .\end{cases}
$$

The crisp set $L_{w /}$ of Concentration levels that belong to Iow water quality at check-point $I$ is defined as

$$
L_{w l}=\left\{c_{w l}: \mu\left(c_{w l}\right)=\mathrm{I}\right) \quad w \Rightarrow i, j .
$$

Graphically the characteristic functions corresponding to $L_{i j}$ and $L_{j l}$ can be represented as Step functions as shown in figures I and 2 respectively. These definitions of low water quality lead to the following deterministic constraints in the management model:

$$
\begin{aligned}
& c_{i t} \geqslant c_{i l}^{\mathrm{L}} \quad \forall i, l, \\
& c_{j l} \leqslant c_{j l}^{\mathrm{H}} \quad \forall i, l .
\end{aligned}
$$

When the water quality indices are random variables chance constraints are introduced in place of the deterministic constraints. The random variables corresponding to $c_{i l}$ and $c_{j}$ are denoted as $C_{i j}$ and $C_{j}$

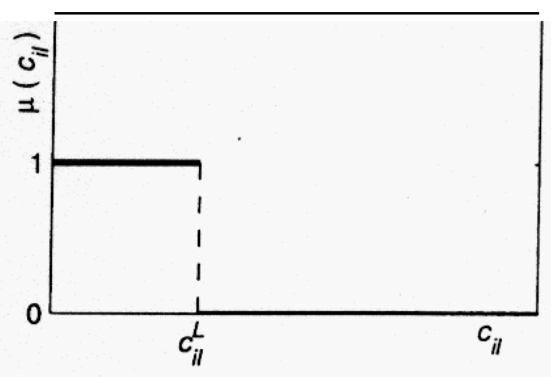

Figure 1. Characteristic function lor $\boldsymbol{L}_{i l}$

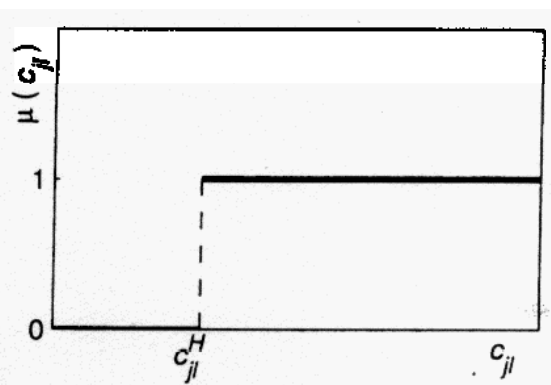

Figure 2. Characteristic function for $L_{j l}$.

respectively. The chance constraint corresponding to $c_{i}$ ensures that the risk of low water quality, that is the probability that the concentration level is less than $c_{i l}^{\mathrm{L}}$, is constrained by a specified upper limit $\gamma_{i t}$. Similarly, the chance constraint corresponding to $c_{j i}$ ensures that the risk oflow water quality, that is the probability that the concentration level is greater than $c_{j l}^{\mathrm{H}}$, is constrained by a specified upper limit $\gamma_{j i}$. Mathematically these chance constraints are expressed as follows:

$$
\begin{aligned}
& P\left(C_{i l} \leqslant c_{i l}^{\mathrm{L}}\right) \leqslant \gamma_{i l}, \\
& P\left(C_{j l} \geqslant C_{j l}^{\mathrm{H}}\right) \leqslant \gamma_{j l} .
\end{aligned}
$$

Two observations are made with respect to these chance constraints:

(I) Any concentration level that is greater than but very close to $c_{j, i}^{\mathrm{L}}$ and that is less than but very close to $c_{j 1}^{\mathrm{H}}$ is not considered as a low water quality. This leads to stringent definitions of low water quality.

(2) Fining the upper bounds $\gamma_{i t}$ and $\gamma_{j i}$ for the risks of low water quality is quite arbitrary. Further, any water quality situation having risks higher than $\gamma_{\text {if }}$ and $\gamma_{j,}$ even by an infinitesimal amount. is excluded.

To overcome these limitations and to account for vagueness in the description of low water quality, a bzzy definition is introduced in place of the crisp defini- 
in of low Water quality. The set. of concentration levels rresponding to the low water quality at check-point $/$ defined as a fuzzy set $W_{w i}(w \Rightarrow i, j)$ instead of the crisp if $L_{k, j}$ given by (3). Each concentration level in the izzy set $W_{k / i}^{\prime}$ is assigned a membership value that lies I the closed interval $[0,1]$. Mathematically the fuzzy set $V^{\prime}{ }^{\prime}$, is expressed as follows:

$$
W_{w l}=\left\{c_{w l}: 0 \leqslant \mu w_{w l}\left(c_{w l}\right) \leqslant \mathrm{I}\right) \quad \boldsymbol{w} \Rightarrow \boldsymbol{i}, \boldsymbol{j} .
$$

$\Omega$ the crisp definition of low water quality, each consentration level in the crisp set $L_{k / /}$ is assigned a member. ship value of either one or zero depending on whether that concentration level corresponds to low water quality or not. On the other hand, the fuzzy set $W_{w /}$ allows partial membership also for the concentration levels. The membership value indicates the degree of compatibility of the concentration level with the notion of low water quality. The membership function that assigns membership values to the elements of the fuzzy set of low water quality thus modifies the conventional definition of low water quality and makes it more realistic. Figures 3 and $\mathbf{4}$ show examples of membership functions of the fuzzy sets $\boldsymbol{W}_{,}$, and $W_{y \prime}$ of low water quality. It may be seen from figure 3 that the concentration levels greater than $c_{i l}^{\mathrm{L}}$ also correspond to low water quality but to a lesser degree than those smaller than $c_{i l}^{\mathrm{L}}$. In figure $3, c_{i l}^{D}$ corresponds to the desirable level for the

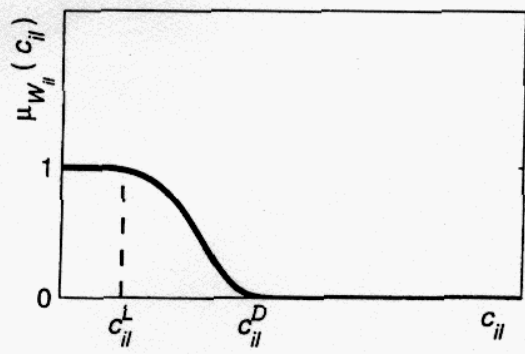

Figure 3. Membership function for $W_{i r}$

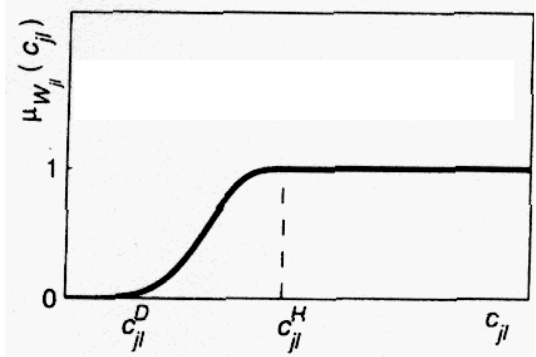

Figure 4. Membership function for $W_{j}$. water quality index $\mathbf{i}$. It may he noted that $c_{i l}^{\mathrm{L}}$ is less than c. D. Similarly, it may be seen from figure 4 that the concentration levels less than $c_{j i}^{\mathrm{H}}$ also correspond to low water quality hut to a lesser degree than those greater than $h$. Mathematically the membership functions corresponding to $W_{i l}$ and $W_{i l}^{\prime}$ may be expressed as follows:

$\mu_{W_{i l}}\left(c_{i l}\right)= \begin{cases}\exp \left(\frac{a_{1 i l}\left(c_{i l}\right)^{n_{i l}}}{c_{i l}-c_{i l}^{\mathrm{D}}}\right), & 0 \leqslant c_{i l}<c_{i l}^{\mathrm{D}}, \\ 0, & c_{i l} \geqslant c_{i l}^{\mathrm{D}},\end{cases}$
$\mu_{W_{i j}}\left(c_{j l}\right)= \begin{cases}1-\exp \left(\frac{a_{1 j l}\left(c_{j l}\right)^{n_{i j}}}{c_{j l}-c_{j l}^{\mathrm{H}}}\right), & 0 \leqslant c_{j l}<c_{j l}^{\mathrm{H}}, \\ 1 & c_{j l} \geqslant c_{j l}^{\mathrm{H}},\end{cases}$

where $a_{1 i,}, a_{1, i}, n_{1 i l}$ and $n_{1, i}$ are parameters of the membership functions. These parameters may he assigned ron-zero positive values depending on the desired shape of the membership functions. For the membership function $\mu_{W_{i}}\left(c_{i l}\right)$ shown in figure 3 , the values of the parameters $a_{1 i l}$ and $n_{|j|}$ may be so assigned that the membership value corresponding to the permissible level $c_{i l}^{\mathrm{L}}$ is approximately equal to one (i.e. $\left.\mu_{W_{i l}}\left(c_{i l}^{\mathrm{L}}\right) \approx \mathrm{I}\right)$. Similarly, for the membership function $\mu_{\mathrm{W}_{j l}}\left(c_{j l}\right)$ shown in figure 4 , values for $a_{1 j l}$ and $n_{|j|}$ may be selected such that the membership value corresponding to the desirable level $c_{j l}^{\mathrm{D}}$ is approximately equal to zero (i.e. $\mu_{W_{i l}}\left(c_{i l}^{\mathrm{D}}\right) \approx 0$ ). In generat, assignment of numerical values to these parameters is governed by the permissible and desirable levels of the water quality index and the desired shape of the membership function. The membership functions discussed above are exponential type. Nevertheless. other types of membership function, such as linear or power type, may also be assigned for the fuzzy set of low water quality. For example. linear membership functions in the closed intervals $\left[c_{i l}^{\mathrm{L}}, c_{i j}^{\mathrm{D}}\right]$ and $\left[c_{i l}^{\mathrm{D}}, c_{i l}^{\mathrm{H}}\right]$ may be used for the furry sets $W_{i}$ and $W_{i l}$ respectively. The aspirations and requirements of the pollution control agency may be taken as the deciding factors in setting the guidelines for Selection of appropriate membership functions for the fuzzy sets of low water quality.

\subsection{Fuzzy rick of low water quality}

The definition of low water quality as a fuzzy event necessitates appropriate modification of the risk of $10 \mathrm{w}$ water quality given by the left-hand side of the inequalities $(6)$ and (7). The modification of the risk of low water quality is introduced using the concept of probability of a fuzzy event (Zadeh 1968). The risk of low water quality is defined as the probability of occurrence 
of the fuzzy event of Iow water quality. Mathematically this can be stated as follows:

fuzzy risk $=\boldsymbol{P}$ (fuzzy event of low water quality)

$$
=\bar{P} \text { (low water quality), }
$$

where $\tilde{P}$ denotes the probability of a fuzzy event. Zadeh (1968) has defined the probability of a fuzzy event $A_{\mathrm{f}}$ as follows:

$$
\tilde{P}\left(A_{\mathrm{f}}\right)=\int_{\mathbf{R}^{n}} \mu_{A_{f}}(y) \mathrm{d} P,
$$

where $\mathbf{R}^{\prime}$ is Euclidean $n$ space, $\mu_{A_{j}}(y)$ is the membership function of the fuzzy event $A_{\mathrm{f}}$ and $\mathrm{P}$ is a probability measure over $\mathbf{R}^{\prime \prime}$. A point in $\mathbf{R}^{n}$ is denoted by y. $P\left(A_{f}\right)$ may be rewritten using $\mathrm{d} P=f(y) \mathrm{dy}$ as follows:

$$
\tilde{P}\left(A_{\mathrm{f}}\right)=\int_{\mathbf{R}^{n}} \mu_{A_{\mathrm{f}}}(y) f(y) \mathrm{d} y
$$

where $f(\gamma)$ is the PDF of the random variable Y. For the fuzzy event of low water quality, $\mathrm{R}$ " is a one-dimensional space $(n=\mathrm{I})$ of concentration levels defined by $[0, \infty]$. The upper limit $\infty$ of Concentration level is used here only for mathematical convenience. Physically, this upper limit will have a finite value for the concentration level. The fuuy risk $r_{w l}\left(w \Rightarrow i_{\mathrm{s}} j\right)$ of low water quality can then be defined as follows:

$$
r_{w l}=\int_{0}^{\infty} \mu_{W_{w l}}\left(c_{w l}\right) f\left(c_{w l}\right) \mathrm{d} c_{w l} \quad \psi \Rightarrow i, j
$$

where $\mu_{W_{w \prime}}\left(c_{w l}\right)$ is the membership function of the fuzzy set $W_{w}$ of $l o w$ water quality and $f\left(c_{\mathrm{w} /}\right)$ is the PDF of the concentration level of water quality index $w$ at the check-point $I$ in the river system. Based on the PDF $f\left(c_{w^{\prime}}\right)$ of the water quality index $w$ and the membership function $\mu_{W_{w s}}\left(c_{w l}\right)$ of the fuzzy set $W_{w /}$ of low water quality, direct or numerical integration may be performed to evaluate the fuzzy risk $r_{w}$. The risk defined by (15) will be used in the subsequent sections of the paper to model the uncertainty. It may be noted that. when (I) and (2) are substituted successively in (IS) with $w$ replaced by $i$ and $j$ respectively, and the fuzzy set $\mathrm{W}$," replaced by the crisp set $L_{\|}$, we obtain the Conventional definitions for risk of low water quality given by the lefthand rides of the inequalities (6) and (7). Thus. the crisp definition of low water quality may he considered as a particular case of the more general fuzzy-ser-based definition. The definition of probability of a fuzzy event given by Zadeh (1968) acts as an effective tool in linking the uncertainty due to vagueness in the definition of low water quality and the uncertainty due to randomness of the water quality index. The concept of fuzzy risk is discussed in the following Section.

\subsection{Low fuzzy risk as a fuzzy set}

Instead of assigning arbitsary upper bounds for the risk of low water quality as given in the chance constraints (6) and (7), the concept of low furry risk is introduced. The low fuzzy risk of low water quality at the cheek-point I is represented as a fuzzy set $R_{w /}$. Different risk levels that belong to the fuzzy set $R_{w 1}$ are assigned membership values between zero and one depending on the conformity of the risk levels with the notion of low risk. The membership function, denoted by $\mu_{R_{w l}}\left(r_{w l}\right)$ of the fuzzy set of low risk is essentially a mapping from the set of risk levels $[0, \mathrm{I}]$ to the set of membership values [0, I]. Different membership func tions that are monotonically non-increasing functions; of risk level can be assigned for the fuzzy set $R$, Figure 5 shows a suitable membership function for the fuuy set of low risk. Mathematically this membership, function can be expressed as follows:

$\mu_{R_{w l}}\left(r_{w l}\right)= \begin{cases}\exp \left(\frac{a_{2 w l}\left(r_{w l}\right)^{n_{2 w l}}}{r_{w l}-r_{w l}^{\mathrm{M}}}\right), & 0 \leqslant r_{w l}<r_{w l}^{\mathrm{M}}, \\ 0, & r_{w l}^{\mathrm{M}} \leqslant r_{w l} \leqslant 1 \quad \mathrm{w} \Rightarrow i, j,\end{cases}$

where $a_{2 w /}$ and $n_{2 w /}$ are parameters of the membership function and $r_{w l}^{\mathrm{M}}$ is the maximum permissible risk level. This particular exponential-type membership function is used in the model fomulation, as it is very general in providing a wide choice of membership functions based on the parameters $a_{2 w}$ and $n_{2 w}$. However, other corms of membership functions such as linear or power types may also be used for the fuzzy set of low risk. The parameters $a_{2 w /}$ and $n_{2 w /}$ may be assigned non-zero positive values such that the membership walues of the acceptable and maximum permissible risk levels are nearly equal to one and zero respectively. The argument $r_{11}$ in the membership function given by (16) can be sutstituted from (IS). Equation (I5) evaluates the fuzzy risk of the event of low water quality, and the membership

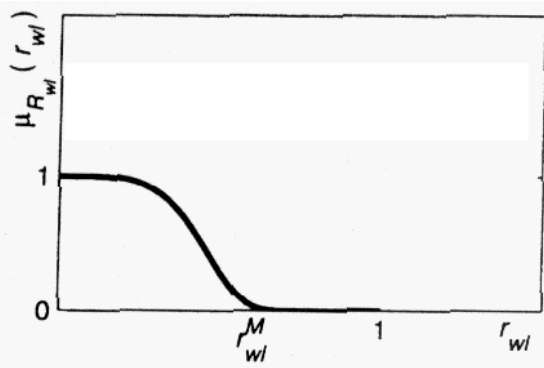

Figure 5. Membership function for the fuzzy set $R_{w l}$ 
nction defined by (16) assigns a membership value to is risk in the fuzzy set of low risk. Thus the two levels of fuzziness, one of low water quality and the other of low risk, haw been quantified using fuzzy sets and the associated membership functions. The concepts discussed in this section are used in developing the fuzzy optimization model for water quality management of a river system.

The goals of the pollution control agency and the dischargers are transformed to fuzzy goals in the next section using fuzzy sets. The fuzzy goals are then used in formulating the fuzzy decision for the water quality management problem.

\section{Fuzzy optimization model}

\section{I. Waler quality management goals}

For the sake of generality of the model, two types of check-point, depending on whether the water quality indices are deterministic or probabilistic at the check-point, are considered in the model formulatisn. for example, a river system may have regulated deterministic. Row (e.g. flow from a reservoir with a fixed policy of operation) in some reaches and hence the water quality indices at the check-points in those reaches may be considered as deterministic. Let $N_{5}$ denote the number of check-points where the water quality indices are probabilistic. The water quality indices are deterministic for the remaining $N_{Q}-N_{S}$ check-points, where $N_{q}$ denotes the total number of check-points in the river system (table I). That is, the water quality indices are probabilistic at the checkpoints I to $N_{S}$ and are deterministic at the checkpoints $N_{y}+$ I to $N_{0}$. The concentrations of the deterministic water quality indices are denoted as $<_{+}$and $c_{v j j}$. When the water quality indices are probabilistic at a check-point $l$, the randomness has to be incorporated in the definition of related water quality goals of the pollution control agency.

3 I.I. Goats of the pollution control agency. These are ats follows.

Grokl $E_{\mathrm{w} /}$ Make the concentration level $c_{d w j}$ of the water quality index $w(w \Rightarrow i, j)$ at the check-point $\mathrm{I}$ as close as possible to the desirable level $\$ 0$ that the water quality at the check-point $/$ is enhanced for all $\because$ and $\mathrm{I}=\mathrm{N},+\mathrm{I}$ to $N_{q}$.

Goal $G_{w}$ Make the risk $r_{w i}$ of low water quality with respect to the water quality index $w(w \Rightarrow i, ;)$ at the check-point / as low as possibie far all $w$ and $\mathrm{I}=\mathrm{I}$ to $N_{S}$.

3.1.2. Cool of the dischargers. This is as follows
Goal $F_{\text {rmm }}$ Make the fraction removal level $x_{\text {N.m }}$ as close as possible to the aspiration level $x_{w m n}^{L}$ for all $\boldsymbol{w}(w \Rightarrow i, j)$ and $n$.

The quantities of interest are the concentration level $c_{d x+y}$ of the water quality index, the risk $r_{w l}$ of low water quality and the fraction removal levels $x_{\text {кетr }}$ of the pollutants that affect the concentration levels of the water quality indices. The quantity $x_{\text {wmn }}$ is the fraction removal level of the pollutant $n$ from the discharger $m$ to control the water quality index $w(w \Rightarrow i, j)$. The aspiration level of tht discharger $\boldsymbol{m}$ with respect to $x_{w m n}$ is represented as $x_{w m n}^{\mathrm{L}}$. The corresponding thaximum fraction removal level acceptable to the discharger $m$ is represented as $x_{w m n}^{\mathrm{M}}$.

Using the fuzzy decision proposed by Bellman and Zadeh (1970), and the subsequently developed fuzzy muftiobjective optimization based on the fuzzy decision (Zimmermanty 1978, 1985, Feng 1983, Kindler 1992, Rao 1993, Sakawa 1995), the fuzzy decision $Z$ for the water quality management problem may be given as follows:

$$
\begin{array}{r}
Z=\left[\bigcap_{i, l} G_{i l}\right] \cap\left[\bigcap_{j, l} G_{j l}\right] \cap\left[\bigcap_{i, l} E_{i l}\right] \\
\bigcap\left[\bigcap_{j, l} E_{j l}\right] \cap\left[\bigcap_{i, m, n} F_{i m n}\right] \cap\left[\bigcap_{j, m, n} F_{j m n}\right] .
\end{array}
$$

The membership function corresponding to the decision $Z$ is given by

$$
\begin{aligned}
\mu_{Z}(X)= & \underset{i, j, l, m, n}{\operatorname{minimum}}\left[\mu_{G_{i l}}\left(r_{i l}\right), \mu_{G_{j l}}\left(r_{j l}\right), \mu_{E_{i l}}\left(c_{d i l}\right),\right. \\
& \left.\mu_{E_{j l}}\left(c_{d j l}\right), \mu_{F_{\text {mmn }}}\left(x_{i m n}\right), \mu_{F_{j m n}}\left(x_{j m n}\right)\right],
\end{aligned}
$$

where Xis the space of alternatives composed of $r_{w /}, c_{d w /}$ and $x_{w m n}\left(w \Rightarrow i_{s} j\right)$. The corresponding optimal decision $X^{*}$ is given by

$$
\mu_{Z}\left(X^{*}\right)+\lambda^{*}=\max _{X \in Z}\left[\mu_{Z}(X)\right] .
$$

The details of the membership functions of the various fuzzy goals are discussed in the following section.

\subsection{Membership functions for the fuzzy goal}

3.2.1. Goal $G_{w 1}$. The membership function (16) for the low risk given in section 2.4 can he considered as the membership function for the fuzzy goal $G_{w l}, l=\mathrm{I}$ to $N_{\text {s. }}$. The pollution control agency may set acceptable and maximum permissible risk levels for the violation of water quality standard. The parameters $a_{21}$ and $n_{2 w /}$ may be assigned appropriate non-zero positive values so that the membership values of the acceptable and maximum permissible risk levels are nearly equal 
to one and zero respectively. The membership function for the fuzzy goal $G_{\text {wy }}$ (with $R_{\text {ry }}$ in (16) replaced by $\left.G_{w 1}\right)$ is given as follows:

$$
\mu_{G_{w l}}\left(r_{w l}\right)= \begin{cases}\exp \left(\frac{a_{2 w l}\left(r_{w l}\right)^{n_{2 w l}}}{r_{w l}-r_{w l}^{\mathrm{M}}}\right), & 0 \leqslant r_{w l}<r_{w l}^{\mathrm{M}}, \\ 0, & r_{w l}^{\mathrm{M}} \leqslant r_{w l} \leqslant \mathbf{I} \boldsymbol{w} \Rightarrow i, j .\end{cases}
$$

The membership function for the fuzzy goal $G_{\text {wy }}$ may be interpreted as the variation in the satisfaction level of the pollution control agency with respect to the risk. It may be noted that a stringent specification of risk level is absent and instead, a wide range, even from zero to one, of risk levels can be incorporated using appropriate membership functions. This provides a wider perspective for uncertainty modelling. In addition to this, the risk itself is evaluated after incorporating the vagueness present in the definition of low water quality.

3.2.2. Goal $E_{\text {ir }}$ The pollution control agency sets up a desirable level $c_{d i l}^{\mathrm{D}}$ and a minimum permissible level $c_{d i t}^{\mathrm{L}}$ for the water quality index $i$ at the check-point $l\left(l=N_{S}+\mathrm{I}\right.$ to $\left.N_{f}\right)$. A parametric membership function that is nonlinear in the domain $\left[0, c_{d i l}^{D_{1}}\right]$ may be considered for the fuzzy goal $E_{i l}$. An example of such a membership function is shown in figure 6. Mathematically this membership function can be expressed as follows:

$$
\mu_{E_{i l}}\left(c_{d i l}\right)= \begin{cases}1-\exp \left(\frac{a_{3 i l}\left(c_{d i l}\right)^{n_{3 i}}}{c_{d i l}-c_{d i l}^{\mathrm{D}}}\right), & 0 \leqslant c_{d i l}<c_{d i l}^{\mathrm{D}}, \\ 0, & c_{d i l} \geqslant c_{d i l}^{\mathrm{D}},\end{cases}
$$

where $a_{3 i l}$ and $n_{3 / i}$ are the parameters of the membership function. These parameters are assigned non-zero positive values such that the membership values corresponding to the desirable and minimum permissible levels of $c_{d i l}$ are nearly equal to one and zero respectively. The membership function for the fuzzy goal $E_{\text {dil }}$

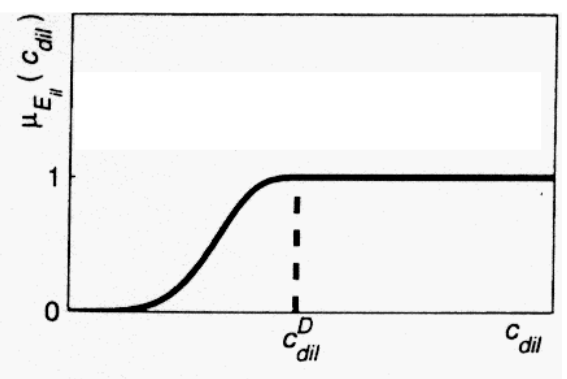

figure 6. Membership function for the goal $E_{i t}$ may be interpreted as the variation in satisfaction level of the pollution control agency with regard to the concentration $c_{d i l}$ of the water quality index $i$ at the check. point 4 . The satisfaction of the pollution control agency decreases as the concentration level $c_{d i l}$ of the water quality index decreases from $c_{\text {ifil }}^{\mathrm{D}}$.

3,2,3. Goal $E_{j I}$ The pollution control agency sets up a desirable level $c_{d i j}^{\mathrm{D}}$ and a maximum permissible level $c_{d i l}^{\mathrm{H}}$ for the water quality index $\dot{j}$ at the check-poi"! $l\left(l=N_{S}+\right.$ I to $\left.N_{q}\right)$. A parametric membership function that is nonlinear' in the domain $\left[0, c_{d j i}^{\mathrm{H}}\right]$ may be considered for the fuzzy goal $E_{j i}$. An example of such a membership function is shown in figure 7. Math. ematically this membership function can be expressed as follows:

$$
\mu_{E_{j l}}\left(c_{d j l}\right)= \begin{cases}\exp \left(\frac{a_{3 j l}\left(c_{d j l}\right)^{n_{3 j}}}{c_{d j l}-c_{d j l}^{\mathrm{H}}}\right), & 0 \leqslant c_{d j l}<c_{d j l}^{\mathrm{H}}, \\ 0, & c_{d j l} \geqslant c_{d j l}^{\mathrm{H}},\end{cases}
$$

where $a_{3 j /}$ and $n_{3 j l}$ are the parameters of the membership function. These parameters are assigned non-zero positive values such that the membership values corresponding to the desirable and permissible levels of $c_{d j l}$ are nearly equal to one and zero respectively. The membership function for the fuzzy goal $E_{d j l}$ may be interpreted as the variation in satisfaction level of the pollution control agency with regard to the concentration $c_{d j l}$ of the water quality index $\mathbf{j}$ at the check-point $l$. The satisfaction of the pollution control agency increases as the concentration level $c_{d j t}$ of the water quality index decreases from $c_{d i l}^{\mathrm{H}}$.

3.2.4. Goal $F_{w m n}$ The membership function for the fuz* zy goal $F_{w m n}\left(w^{*} i, j\right)$ is shown in figure 8 . The exponent $\beta_{w m n}$ appearing in the membership function is a positive real number. The fraction removal level $x_{\text {rum }}^{\mathrm{K}}$ corresponding to the aspiration level of the discharger $m$ with regard to $x_{w m n}$ is assigned a membership value

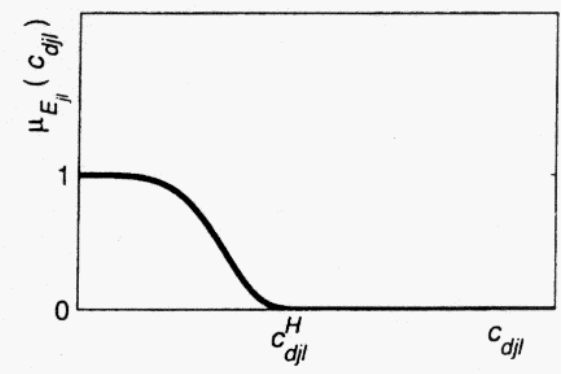

Figure 1. Membership function for the goal $E_{j l}$. 


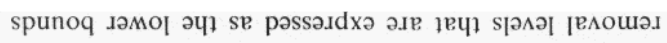

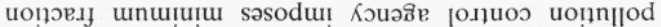

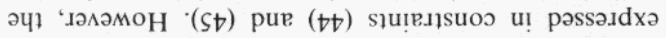

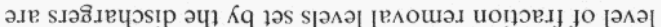

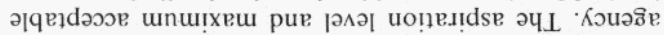

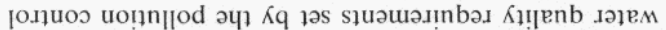

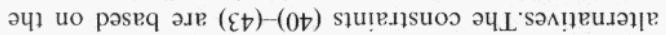

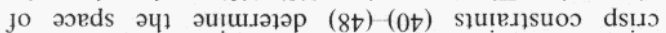

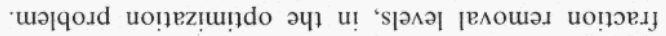

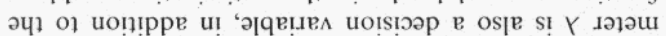

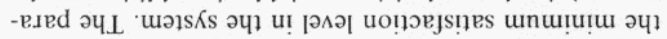

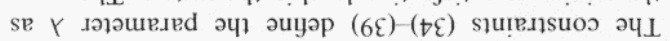

$$
\begin{aligned}
& \text { I }>Y>0
\end{aligned}
$$

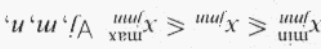

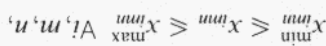

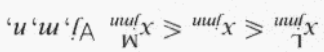

$$
\begin{aligned}
& \text { ' } u \text { ' } u{ }^{\prime} ! \mathrm{A} \quad{ }^{\text {"un! }} x>{ }^{\text {"uu! }} x>{ }^{\text {"un! }} x
\end{aligned}
$$

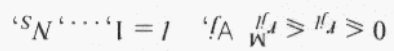

$$
\begin{aligned}
& { }^{\prime} S_{N} \cdot \cdots \cdot \mathrm{I}=1 \quad \text { "? } \quad{ }_{W}^{\prime \prime}>n_{1}>0
\end{aligned}
$$

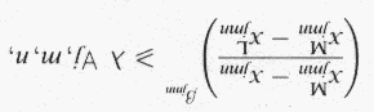

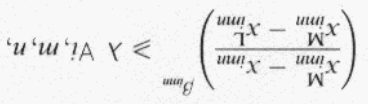

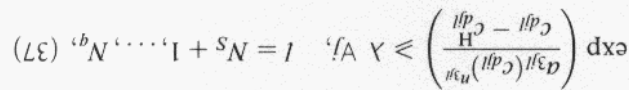

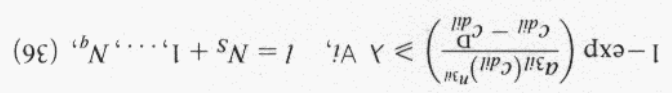

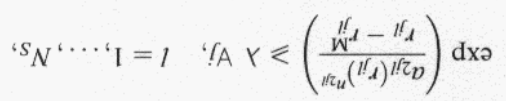

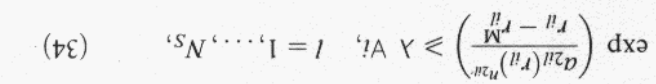

$$
\text { Y วz!̣!̣тxน }
$$

ol toวlqus

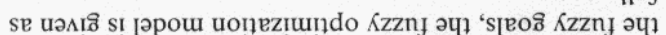

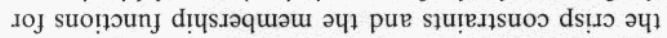

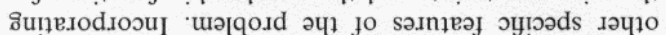

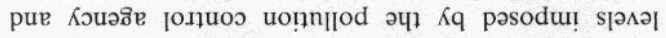

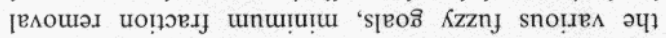
Jo suo!̣’uny d!̣

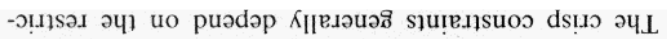

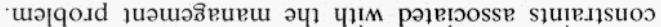

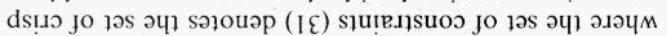

$$
\text { ' } 1>Y>0
$$$$
\text { ' } 4 \text { A } \quad 0>(X)^{4} B
$$

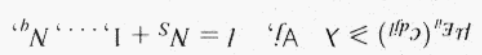

(LZ) $\quad{ }^{b} N \cdot \cdots \cdot$ I $+s_{N}=1 \quad$ '? $\left.\quad Y<\left(I ! p_{\jmath}\right)^{n}\right]_{H}$

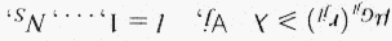

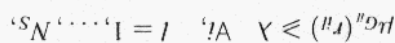

ol 102 [qus

$$
\text { Y วz!u!xвu }
$$

:SMOाIOJ se passə.Idxə

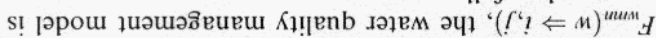

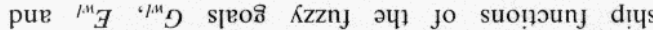

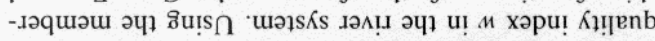

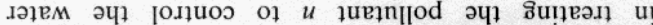

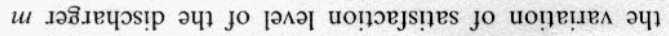

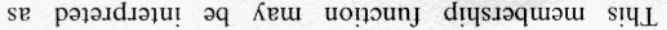

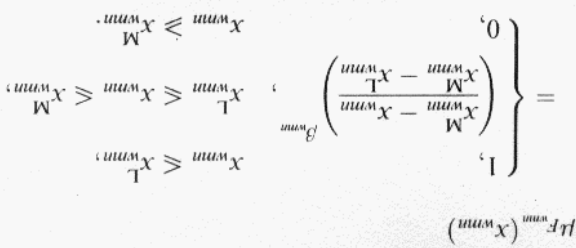

$$
\begin{aligned}
& \text { ( } \varepsilon)
\end{aligned}
$$

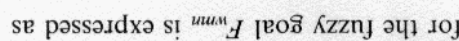

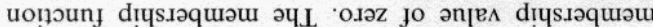

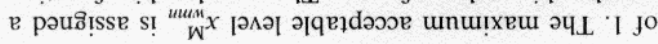
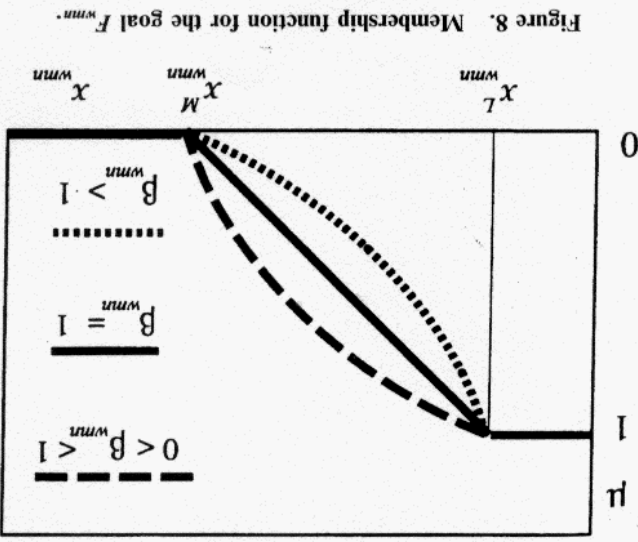
$x_{i m n}^{\min }$ and $x_{j m n}^{\min }$ in constraints (46) and (47). The upper bounds $x_{i m n}^{\max }$ and $x_{j m n}^{\max }$ in these constraints represent the technologically possible maximum fraction removal levels. Observing that the maximum acceptable level $x_{\text {timn }}^{\mathrm{M}}$ of pollutant treatment cannot exceed the technologically possible upper limit $x_{w m n}^{\max }$, the constraints (44) and (46) can be simplified to a single constraint given by (49) and, similarly, the constraints (45) and (47) can be simplified to a single constraint (50), as follows:

$$
\begin{aligned}
& \max \left(x_{i m n}^{\mathrm{L}}, x_{i m n}^{\min }\right) \leqslant x_{i m n} \leqslant x_{i m n}^{\mathrm{M}} \quad \forall i, m, n, \\
& \max \left(x_{j m n}^{\mathrm{L}}, x_{j m n}^{\mathrm{min}}\right) \leqslant x_{j m n} \leqslant x_{j m n}^{\mathrm{M}} \quad \forall j, m, n,
\end{aligned}
$$

The concentration levels $c_{b / t}$ and $c_{d \mathrm{w} /}(w \Rightarrow i, j)$ of the water quality index at the check-point $I$ can be related to the fraction removal levels $x_{\text {mm }}$ with the help of transfer functions. These transfer functions can be derived using appropriate mathematical models that determine the spatial distributions of the water quality index due to the pollutants in the river system. The risk $r_{w / t}$ of low water quality at the check-point I can be evaluated using (15). The $\operatorname{PDF} f\left(c_{w l}\right)$ is derived from the PDFs of the various random elements that affect the concentration level $c_{w l}$. The PDF thus derived will be in terms of the vector of fraction removal levels $x_{w m n}$. The derivation of PDF depends an the problem at hand. The example given in section 4 illustrates this with respect to the DO deficit as the water quality index that is random due to the random nature of river Row. Substitution for $r_{w l}, c_{\mathrm{w} /}$ and $c_{d w l}$ in the constraints of the above optimization model transforms the constraints in terms of the fraction removal levels. In general, the resulting model will be a nonlinear optimization model and suitable algorithms need to be adopted to solve the model. The solution of the model gives $X^{*}$ and $\lambda^{*}$ where $X^{*}$ is the vector of optimum fraction removal levels and $\lambda^{*}$ is the man-min satisfaction level in the system. The application of the fuzzy optimization model to a river system is discussed in the following section.

\section{Model application}

Application of the model is illustrated using a hypothcticst river system shown in figure 9. Description of the river system with respect to the notation used in the model is given in table 2. To keep the emphasis on simultaneous treatment of randomness and vagueness, the illustration is kept simple with respect to other detailed aspects of water quality modelling for a river system. For example, more detailed water quality models (see far example Gromiec pl al. (1983). Thomann and Mueler (1987) and james and Elliot (1993)) may be used in place of the one-dimensional BOD-DO model used in the illustration. The effects due to the randomness of other variables such as the

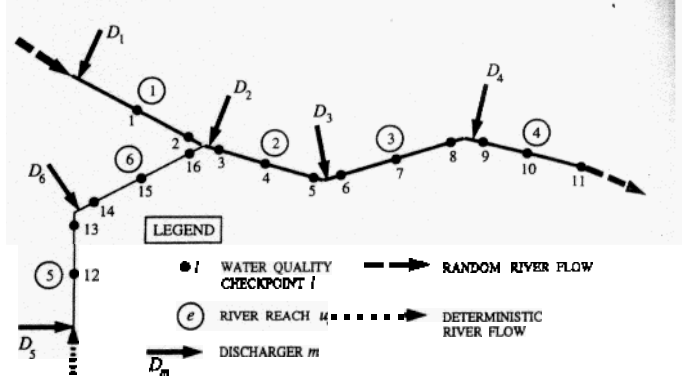

Figure 9. A hypothetical river system

temperature and reaction rate coefficients that affect the probability distribution of the water quality index may also be treated in a similar way as discussed in the illustration for random river flow. The objective of the illustrative example presented in this section is to demonstrate the applicability of the fuzzy probabilistic model to a simplified but realistic hypothetical river system.

River reaches 1-4 form the main stem of the river network. River reaches 5 and 6 form a tributary to the maits stem. The river Row $Q$ in the main stem of the river network is considered as a random variable. The PDF and the cumulative distribution function (CDF) of the flow $Q$ are assumed to be known. All other Rows such as the tributary Row and effluent Rows are assumed to be deterministic. The magnitude of the deterministic Row in the tributary which is composed of reaches 5 and 6 is $3.9821 \times 10^{6} \mathrm{~m}^{3} \mathrm{day}^{-1}$. The pollutant in the System is the point sources of BOD waste load. The water quality index of interest is the DO deficit at a finite number of check-points $n$ the river network due to those pointsources of BOD. Water quality is checked at the 16 check-points shown in figure 9 . The data pertaining to the river flows and effluent Rows are given in table 3 . The mean time of Row in the sixth column of table 3 corresponds to the travel time of Row from the beginning to the end of the reach. The middle check-point in each reach corresponds lo half the mean time of Row from the beginning to the end of the reach. The deoxygenalior and rearation rate coefficients, and the saturation DO concentration remain constant for at the checkpoints in the same river reach.

The DO deficit at a check-point can be expressed in terms of the fraction removal levels of BOD associated with various dischargers located upstream of the checkpoint under consideration through the transfer function. The transfer function that expresses the DO deficit at a check-point in terms of the concentrations of the point sources of ROD and the fraction removal levels are obtained using the one-dimensional steady-stale BODDO equations (Gromiec tet al 1983, Thoments and 
Tabla 2. Details of the hypothetical river system.

\begin{tabular}{|c|c|c|c|}
\hline Set & $\begin{array}{l}\text { Description } \\
\text { of the ref }\end{array}$ & $\begin{array}{l}\text { Element } \\
\text { representation }\end{array}$ & $\begin{array}{l}\text { Number } \\
\text { of elements }\end{array}$ \\
\hline$O_{1}$ & Water quality check-points & I & $N_{q}=16$ \\
\hline$B_{M}^{L}$ & Dischargers & $m$ & $N_{d}^{g}=6$ \\
\hline$P_{N}$ & Pollutants: point sources of $\mathrm{BOD}$ & $n$ & $N_{p}=\mathrm{I}$ \\
\hline$T_{P}$ & Uncontrollable sources of pollutants: nil & $P$ & $N_{1}=0$ \\
\hline$V_{A}$ & Water quality indices: $n i l$ desirable level $>$ permissible level & $i$ & $N_{v}=0$ \\
\hline$S_{V}$ & Water quality indices: DO deficit; desirable level < permissible level & $j$ & $N_{s}=1$ \\
\hline
\end{tabular}

Table 3. Efluent flow and river flow data.

\begin{tabular}{|c|c|c|c|c|c|c|c|c|}
\hline \multirow{2}{*}{\multicolumn{4}{|c|}{ Effluent flow data }} & \multicolumn{5}{|c|}{ River Row data } \\
\hline & & & & \multirow[b]{2}{*}{$\begin{array}{c}\text { River } \\
\text { reach } \\
u_{\mathrm{e}}\end{array}$} & \multirow[b]{2}{*}{$\begin{array}{l}\text { mean time } \\
\text { of flow } \\
\text { (days) }\end{array}$} & \multirow[b]{2}{*}{$\begin{array}{l}\text { Deoxygenation } \\
\text { rate constant } \\
\left(\text { day }^{-7}\right)\end{array}$} & \multirow[b]{2}{*}{$\begin{array}{l}\text { Reacration } \\
\text { rate constant } \\
\left(d a y^{-1}\right)\end{array}$} & \multirow{2}{*}{$\begin{array}{c}\text { Saturation } \\
\text { DO } \\
\text { concentration } \\
\left.(m g)^{-1}\right)\end{array}$} \\
\hline Dischatger & $\begin{array}{c}\text { Effuent } \\
\text { fow rate } \\
\left(10^{\prime} \mathrm{m}^{-1} \text { day }{ }^{-1}\right)\end{array}$ & $\begin{array}{c}\text { BOD } \\
\text { concertiation } \\
\left(\mathrm{mg} \mathrm{l}^{-1}\right)\end{array}$ & $\begin{array}{c}\text { DO } \\
\underset{\left(\mathrm{mgl}^{-1}\right)}{\text { concentration }}\end{array}$ & & & & & \\
\hline$D_{1}$ & 2.114 & 1250 & 1.23 & $u_{[}$ & 0.316 & 0.111 & 0.841 & 9.70 \\
\hline$D_{2}$ & 6.321 & 1415 & 2.40 & $u_{2}$ & 0.732 & 0.320 & 0.754 & 9.80 \\
\hline $\mathrm{D}_{3}$ & 7.554 & 2080 & 1.70 & $u_{3}$ & 1.218 & 0.357 & 0.670 & 9.85 . \\
\hline$D_{4}$ & 5.180 & 935 & 2.16 & $u_{4}$ & 1.823 & 0.390 & 0.210 & 9.4) \\
\hline$D_{5}$ & 6.415 & 765 & 1.93 & $u_{5}$ & 0.642 & 0.328 & 0.741 & 9.80 \\
\hline$D_{6}$ & 4.126 & 1880 & 1.80 & $u_{6}$ & 1.312 & 0.378 & 0.532 & 9.90 \\
\hline
\end{tabular}

Muelfer 1987, James and Elliof (993). Different methods that employ the one-dimensional Streeter-Phelps equations to predict the spatial distribution of DO deficit in a river network with multiple reaches are available in literature (see for example Arbabi and Elzinga (1975) and Fugiwara el al, (1986)). A suitable adoption of the model proposed by Fugiwaja el 01. (1986) is used in the present study.

Since only a Single water quality index (DO deficit) and only one type of pollutant (point source of BOD from the dischargers) are considered in this illustrative example, the notation for the differett variables are simplified by retaining only the subscripis I (checkpoint) and $\boldsymbol{m}$ (discharger) with the various quantities of interest. For example, $c_{l}, r_{l}$ and $x_{m}$ denote, the DO deficit at the check-point $\zeta$, the risk of low water quality at the check-point I and the fraction removal level of BOD for the discharger $\boldsymbol{m}$ respectively. Similarly, the goals of the pollution control agency are denoted by $G_{1}$ (for probabilistic case) and $E_{l}$ (for deterministic case), and the goals of the dischargers are denoted by $F_{\mathrm{H} \text {. }}$.

Owing to the random nature of the river Row $Q$ in the main stem of the river network, the $D O$ deficit at a check-point $I(I=I-1 \mathrm{I})$ in the main stem (reaches $I-4$ ) may he considered as a random variable $C_{\text {. }}$. The DO deficit at any check-point $l(l=12-16)$, other than that in the main stem, in the river network is assumed to be deterministic. The deterministic DO deficits at these check-points can be expressed as linear functions of the fraction removal levels using the method given by Fugiwara elal, (1986). The constant term and the coefircients of the fraction removal levels in the DO deficit expressions for the check-points $\mathrm{I}=12-16$ are given in table 4. The DO deficits at these check-points are functions of only the fraction removal levels $x_{5}$ and $x_{6}$ corresponding to the dischargers $D_{5}$ and $D_{6}$ respectively.

Tabla 4. Data for DO deficit expression: $c_{l}(I=12-16)$

\begin{tabular}{lccccccc}
\hline & & \multicolumn{1}{c}{$-1 \times$ following coefficients } \\
\cline { 3 - 8 } Checkpoint $I$ & term & $x_{1}$ & $x_{2}$ & $x_{3}$ & $x_{4}$ & $x_{5}$ & $x_{6}$ \\
\hline 12 & 1.1741 & 0 & 0 & 0 & 0 & 1.0758 & 0 \\
13 & $\mathbf{1 . 8 9 4 3}$ & 0 & 0 & 0 & 0 & 1.8168 & 0 \\
14 & $\mathbf{2 . 0 5 8 9}$ & 0 & 0 & 0 & 0 & 1.7976 & 0 \\
15 & 6.9033 & 0 & 0 & 0 & 0 & 3.0579 & 3.6612 \\
16 & $\mathbf{9 . 1 2 2 5}$ & 0 & 0 & 0 & 0 & $\mathbf{3 . 5 5 3 3}$ & 5.4391 \\
\hline
\end{tabular}


For example, the DO deficit at the check-point 15 is expressed as follows using the data given in table 4 :

$$
c_{15}=6.9033-3.0579 x_{5}-3.6612 x_{6} .
$$

Treatment of the random variable $\sigma_{1}$ of the DO deficit at the check-points $1-11$ is considered next. Following Fugiwara ef al. (1986), the DO deficit $C_{1}$ at the checkpoint $I$ can be expressed in general form as

$$
C_{l}=\frac{A_{l} Q+B_{l}}{Q+V_{l}}, \quad l=1, \ldots, 11,
$$

where $A_{l}$ is a Constant depending on the BOD and DO deficit with which the river Rows enter the main stem (at the beginning of reach I) and tributary (at the beginning of reach 5) of the river network, $B_{l}$ is a function of the vector $\boldsymbol{X}$ of fraction removal levels, and $V_{l}$ is a constant depending $O n$ the deterministic component of the total Row (deteministic component of river Row plus effluent Row) at the check-point $I$. The details of $A_{l}, B_{l}$ and $V_{l}$ at the check-points 1-11 are obtained using the method suggested by Fugiwara et al. (1986) for evaluating the DO deficit at a check-point in a river system. The factor $B_{1}$ is a lineat function of the fraction removal levels Table 5 gives the values for $A_{1}, B_{1}$ and $V_{1}$. In the table, the third column gives the constant term, and the fourth to ninth columns give the coefficients of the fraction removal levels in the expression for $B_{1}$, It may be noted that, in (52), $Q$ should be expressed in cubic metres per day so as to conform to the data given in table 5 .

Owing to the dilution of waste-water flow by the river Row, the DO deficit at a check-point decreases as the river Row increases when all other factors that affect the DO deficit remain invariant (Thomann and Mueller
1987). As a consequence of this, the probability that the DO deficit is less than or equal to a certain DO deficit value $c_{l}$ at the check-point $I$ may be equated to the probability that the river Row is greater than or equal to an associated river Row value 9 , that is

$$
P\left(C_{i} \leqslant c_{l}\right)=P(Q \geqslant q), \quad I=1, \ldots, \text { I . }
$$

Using (\$2) and (53), the CDFF $F_{C_{l}}\left(c_{l}\right)$ of DO deficit at the check-point $l$, can be derived as follows:

$$
\begin{aligned}
F_{C_{l}}\left(c_{l}\right) & =\left(C_{l} \leqslant c_{l}\right) \\
& =P\left(\frac{A_{l} Q+B_{l}}{Q+V_{l}} \leqslant c_{l}\right) \\
& =P\left(Q \geqslant \frac{B_{l}-V_{l} c_{l}}{c_{l}-A_{l}}\right) \\
& =1-P\left(Q \leqslant \frac{B_{l}-V_{l} c_{l}}{c_{l}-A_{l}}\right) \\
& =1-F_{Q}\left(\frac{B_{l}-V_{l} c_{l}}{c_{l}-A_{l}}\right) \\
& =\mathbf{I}-F_{Q}(q) .
\end{aligned}
$$

where $F_{Q}(q)$ is the CDF of river How. The PDF of DO deficit at the check-point $\boldsymbol{I}$ is then obtained by diffetentiating $F_{c}(c)$ with respect to $c$ as follows:

\begin{tabular}{|c|c|c|c|c|c|c|c|c|c|}
\hline \multirow[b]{3}{*}{ Checkpoint / } & \multirow[b]{3}{*}{$A_{i}$} & \multicolumn{8}{|c|}{$B_{I}$} \\
\hline & & \multirow{2}{*}{$\begin{array}{c}\text { Constant } \\
\text { term } \\
\left(\times 10^{7}\right)\end{array}$} & \multicolumn{7}{|c|}{$-10^{7} \times$ followitg coefficients } \\
\hline & & & $x_{1}$ & $x_{2}$ & $x_{3}$ & $x_{4}$ & $x_{5}$ & $x_{6}$ & $\begin{array}{c}V_{l} \\
\left(\times 10^{6}\right)\end{array}$ \\
\hline \multirow[t]{2}{*}{$\mathbf{I}$} & 0 & 0.1429 & $0.127 !$ & 0 & 0 & 0 & 0 & 0 & 0.0213 \\
\hline & 0 & 0.2456 & 0.2318 & 0 & 0 & 0 & 0 & 0 & 0.0213 \\
\hline 3 & 0.1 & 39824 & 0.2318 & 0 & 0 & 0 & 1.4531 & 2.2243 & 4.1741 \\
\hline 4 & 0.0756 & 4.8127 & 0.4066 & 0.8613 & 0 & 0 & 1.3314 & 2.1581 & 4. 1741 \\
\hline 5 & 0.0576 & 5.2659 & 0.5150 & 1.4203 & 0 & 0 & 1.2212 & 2.0673 & 4.1741 \\
\hline 6 & 0.1076 & 5.3484 & 0.51511 & 1.4203 & 0 & 0 & 1.2212 & 2.0673 & 4.2496 \\
\hline 7 & 0.0715 & 8.4192 & 0.645 .7 & 2.0718 & 2.5030 & 0 & 1.1172 & 1.9990 & 4.2496 \\
\hline 8 & 0.0476 & $9.5] 08$ & 0.6727 & 2.2847 & 36782 & 0 & 0.9884 & 1.8315 & 42496 \\
\hline 4 & 0.0976 & 9,5721 & 0.6727 & 2.2847 & 3.6782 & 0 & 0.9884 & 1.8315 & 4.3014 \\
\hline III & 0.0806 & 1.5651 & 0.8887 & 3,1269 & 5.7191 & $1.3[11$ & 1.1520 & 2.1992 & 4.3014 \\
\hline l! & 0.0665 & 16.6962 & 0.9674 & 3,4514 & 6.7123 & 2.0017 & 1] 866$. & 2.2975 & 4.3014 \\
\hline
\end{tabular}

$$
f\left(c_{l}\right)=\frac{\mathrm{d}}{\mathrm{d} c_{l}}\left[F_{C_{l}}\left(c_{l}\right)\right]=-\frac{\mathrm{d}}{\mathrm{d} c_{l}}\left[F_{Q}\left(\frac{B_{l}-V_{l} c_{l}}{c_{l}-A_{l}}\right)\right] .
$$

Derivation of the PDF $f\left(c_{1}\right)$ using $(5,5)$ requires the CDF $F_{Q}(q)$ of the river How to be a differentiable function, but the $\operatorname{CDF} F_{Q}(q)$ may not be available in a closed. form expression in some cases and hence the differentia. tion will not be possible (e.g. the CDF corresponding to

Table 5. Data for DO deficits at checkpoints 1-11. 
[he normally distributed river Row). In such cases, appropriate numerical techniques may be used to determine the PDF of $c_{l}$, Starting with PDF of Q. The differentiation of the known or derived $\operatorname{CDF} \boldsymbol{F}_{Q}(q)$ is carried out with respect to $c_{l}$ after substituting $\left(B_{f}-V_{l} C_{l}\right) /\left(c_{l}-\mathrm{A},\right)$ for $q$ in the expression for $\boldsymbol{F}_{Q}(q)$. Since the management problem is more relevant for low Row conditions, a bounded, exponential distribution for the river Row Q has been used in this example. Such a distribution is commonly used for low Rows in hydrological studies (Yevjewich 1972, Beran and Rodier 1985) The closed-form expression for the $\mathrm{CDF} F_{0}(q)$ available in the case of the bounded exponential distribution makes it possible to obtain the PDF $f\left(c_{l}\right)$ in a closed form which car subsequently be used in (15) to evaluate the risk $r_{i}$. Mathematically the bounded exponential $\mathrm{PDF}$ of the Row is expressed as

$$
f(q)=\theta \exp \left[-\theta\left(q-q_{L}\right)\right], \quad \theta>0, \quad q \geqslant q_{L} .
$$

The values of the parameters $q_{L}$ and 8 of the PDF are $5.8263 \times 10^{6} \mathrm{~m}^{3} \mathrm{day}^{-1}$ and $0.4 \times 10^{-6}$ day m$^{-3}$ respectively. The CDF of the river Row is given as

$$
F_{Q}(q)=\mathrm{l}-\exp \left[-\theta\left(q-q_{L}\right)\right], \quad \theta>0, \quad q \geqslant q_{L} . \text { (57) }
$$

Substituting for $q$ using $\left(B_{l}-V_{l} c_{l}\right) /\left(c_{l}-A_{l}\right)$ in $F_{Q}(q)$ in (54), the CDF of DO deficit is obtained as

$$
F_{C_{l}}\left(c_{l}\right)=\exp \left[-\theta\left(\frac{B_{l}-V_{l} c_{l}}{c_{l}-A_{l}}-q_{L}\right)\right] .
$$

Differentiating the CDF given by (58), the PDF of DO deficit is obtained as

$$
f\left(c_{l}\right)=\frac{\theta\left(B_{l}-A_{l} V_{l}\right)}{\left(c_{l}-A_{l}\right)^{2}} \exp \left[-\theta\left(\frac{B_{l}-V_{l} c_{l}}{c_{l}-A_{l}}-q_{L}\right)\right] .
$$

This PDF of the DO deficit is used for evaluating the risk defined by (15). The membership function $\mu_{W_{1}}\left(c_{l}\right)$ for the fuzzy set of low water quality required in $(15)$ is expressed as

$$
\mu_{W_{l}}\left(c_{l}\right)=1-\exp \left(\frac{a_{1 /}\left(c_{l}\right)^{\mu_{1 /}}}{c_{l}-S_{l}}\right), \quad l=1, \ldots, 11,
$$

where $a_{1 /}$ and $n_{1 / \text { are non }}$ zeto posilive constants and $S_{f}$ is the saluration DO concentration lewel at the checkpoint /. The limits of integration for evaluating the risk are oblained by considering the minimum and maximum values of DO deficit, denoted hy $c_{l}^{\min }$ and $c_{t}^{\operatorname{mix}}$ respecively, as follows. The minimum and maximum values of DO deficit depend on the upper and lower limits respectively of the PDP of the river Row. The minimum DO deficjt $c_{l}^{\mathrm{mm}}$ occurs when the river Row is mitrimum (i.e. as $Q \rightarrow \infty$ ) and the maximum DO deficit $a^{\text {mix }}$ occurs when the river Row is minimum (i.e. $Q=q_{I}$. Thus,

$$
\begin{aligned}
& c_{l}^{\min }=\lim _{Q \rightarrow \infty}\left(\frac{A_{l} Q+B_{l}}{Q+V_{l}}\right)=A_{l}, \\
& c_{l}^{\max }=\left(\frac{A_{l} q_{L}+B_{l}}{q_{L}+V_{l}}\right)
\end{aligned}
$$

The risk of low water quality is then evaluated using (15) as follows:

$$
r_{l}=\int_{c_{l}^{\min }}^{c_{l}} \mu_{W_{l}}\left(c_{l}\right) f\left(c_{l}\right) \mathrm{d} c_{l} .
$$

A crisp constraint for the maximum and minimum concentration levels is written as

$$
c_{i}^{\min } 6 c_{f}^{\max } 6 S_{\%}
$$

Nonlinear membership functions are used for the water quality goals $E_{l}$ at the check-points $\mathbf{1 2 - 1 6}$ where the DO deficit is deterministic, and for the risk goals $G_{l}$ related to the low water quality at the check-points $!-1$ I where the DO deficit is random. Linear membership functions are assigned for the pollutant treatment goals $F_{\mathrm{m}}$. The parameters of the various membership functions are fixed on the basis of the desired shape of the membership functions. Use of these parameters help to design the membership functions so as to reflect the qualitative trends associated with the fuzzy goals of the pollution control agency and dischargers, and the fuzzy sets of low water quality. The membership function given by (22) is used for all the fuzzy goals $E_{l}$ assigning the values 0.01 and 4 to the parameters $n_{3 /}$ and $n_{3 /}$ respectively for all $\mathrm{I}(l=\mathbf{1 2 - 1 6})$. The values of these parameters are so chosen that the membership values corresponding to the DO deficits of $2 \mathrm{mg}^{1^{-1}}$ (acceptable level) and $6 \mathrm{mgl}^{-1}$ (maximum permissible level) are nearly equal to one and zero respectively. The parameter $c_{l}^{\mathrm{H}}$ in the membership function far the goal $E_{l}$ takes the value of the saturation DO concentration $S_{l}$ at the check-point $l$. As an example, the membership function for the goal $E_{12}$ is shown in figure 10. The membership

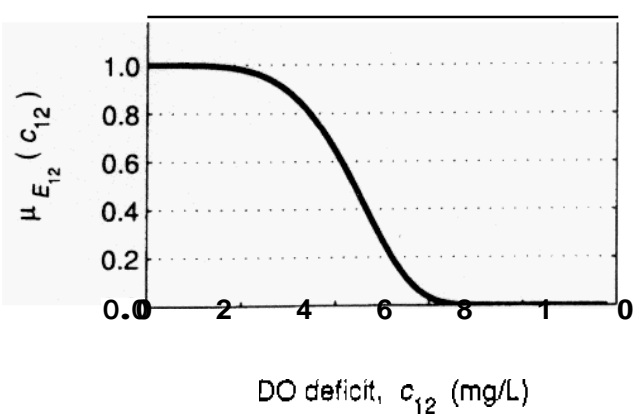

Figure 10. Membership function for the goal $E_{12}$. 
function given by (16) is used for all the fuzzy goals $G_{l}$ The parameters $a_{2 l}, n_{2 l}$ and $r_{l}^{\mathrm{M}}$ of this membership function are assigned the values of 500, 4 and I respectively for all $l(l=1-11)$. The values of these parameters are so chosen that the membership values corresponding to the risk levels of 0.05 (acceptable) and 0.25 (maximum permissible) are nearly equal to one and zero respectively. This membership function is shown in figure I1. A linear membership function is used for the fuzzy goal $F_{m \text { m }}$ and is given as

$$
\mu_{F_{m}}\left(x_{m}\right)= \begin{cases}1, & 0 \leqslant x_{m} \leqslant x_{m}^{\mathrm{L}}, \\ \frac{x_{m}^{\mathrm{M}}-x_{m}}{x_{m}^{\mathrm{M}}-x_{m}^{\mathrm{L}}}, & x_{m}^{\mathrm{L}} \leqslant x_{m} \leqslant x_{m}^{\mathrm{M}}, \\ 0, & x_{m} \geqslant x_{m}^{\mathrm{M}}\end{cases}
$$

The parameters $x_{m}^{\mathrm{L}}$ and $x_{m}^{\mathrm{M}}$ of the membership functions $F_{\mathrm{r}}$ are given in table $\mathbf{6}$. Also given in table $\mathbf{6}$ are the values of the minimum fraction removal level $x_{m}^{\min }$ set by the pollution control agency for the discharger $m$. The membership function for the fuzzy goal $F_{1}$ is shown in figure 12. The membership function $\mu_{W_{1}}\left(c_{l}\right)$ for the fuzzy set of low water quality is given by (60). The values assigned to the parameters $a_{1 /}$ and $n_{1 / \text { are }} 0.01$ and 4 respectively for all $I$ such that the membership values corresponding to the DO deficits of $2 \mathrm{mgl}^{-1}$ (desirable level) a $6 \mathrm{mgl}^{-1}$ (permissible level) are nearly equal to zero and one respectively. As an example. the member-

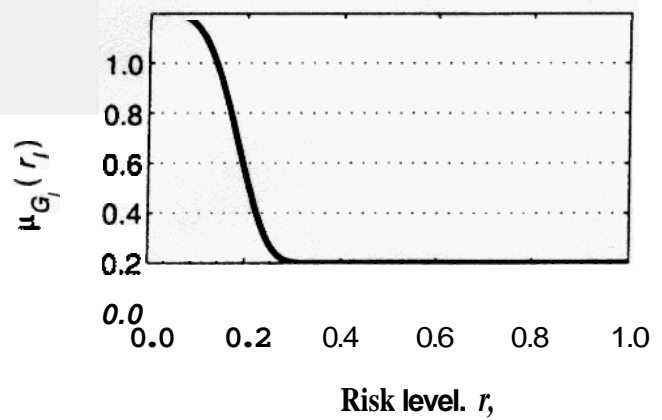

Figure 11. Membership function for the goal $G_{I}$

Table 6. Details of membership functions for goals $F_{m r}$.

\begin{tabular}{lcccc}
\hline Discharger $D_{m}$ & $x_{m+1}^{\mathrm{L}}$ & $x_{m}^{\mathrm{M}}$ & & $\gamma_{m}^{\mathrm{MIN}}$ \\
\hline$D_{1}$ & 0.25 & 0.75 & & 0.30 \\
$D_{2}$ & 0.35 & 0.80 & & 0.30 \\
$I)_{1}$ & 025 & 0.90 & & 0.30 \\
$D_{4}$ & 030 & 0.85 & & 0.30 \\
$D_{5}$ & 0.35 & 0.75 & & 0.30 \\
$I)_{r}$ & 0.30 & 0.90 & & 0.30 \\
\hline
\end{tabular}

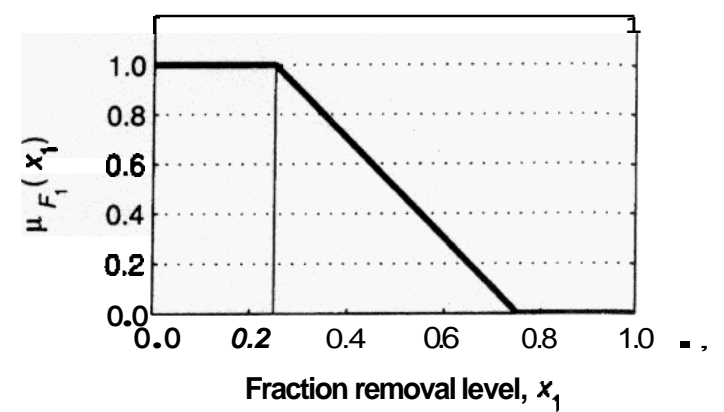

Figure 12. Membership function for the goal $F_{1}$.

ship function $\mu_{W_{11}}\left(c_{11}\right)$ for the fuzzy set of low water quality at the check-point 11 is shown in figure 13 . The fuzzy optimization model for water quality management of the river system shown in figure 9 is now presented as follows:

maximize A

subject to

$$
\begin{aligned}
\exp \left(\frac{500 r_{l}^{4}}{r_{l}-1}\right) \geqslant \lambda, \quad l=1 \ldots . .11, \\
\exp \left(\frac{0.01 c_{l}^{4}}{c_{l}-S_{l}}\right) \geqslant A, \quad l=12 \ldots .16, \\
\frac{x_{m}^{\mathrm{M}}-x_{m}}{x_{m}^{\mathrm{M}}-x_{m}^{\mathrm{L}}} \geqslant \lambda, \quad m=1, \ldots .6, \\
0 \leqslant r_{l} \leqslant 1, \quad l=1 \ldots .11, \\
c_{l}^{\min } \leqslant c_{l}^{\max } \leqslant S_{l}, \quad l=1 \ldots \ldots 1, \\
0 G c_{l} \leqslant S_{l}, \quad l=12 \ldots .16, \\
\max \left(x_{m}^{\mathrm{L}}, x_{m}^{\min }\right) \leqslant x_{m} \leqslant x_{m}^{\mathrm{M}}, \quad m=1, \ldots, 6, \\
0 \leqslant \lambda \leqslant 1 .
\end{aligned}
$$

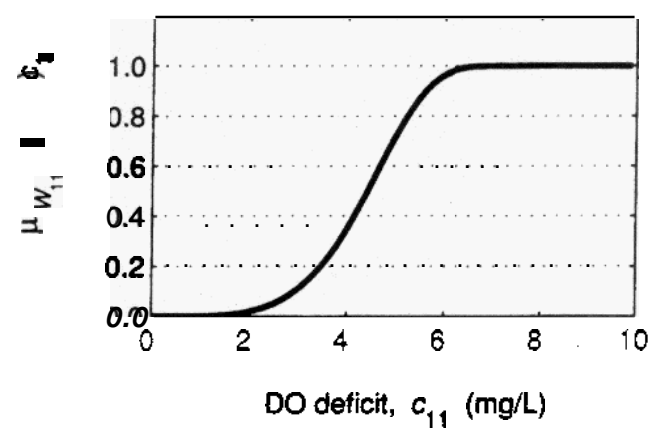

Figure 13. Membership function for the fuzzy set $\boldsymbol{F}_{1}$. 
The nonlinear constraints (67) and (68) render the fuzzy optimization model to be a nonlinear programming problem. The terms $r_{l}$ and $c_{l}$ in the above constraints are bath functions of the fraction removal levels $x_{\mathrm{m}}$. The resulting nonlinear programming problem has been solved using the Optimization Toolbox (The Maths Works, Inc, 1994) available in MATLAB (The Maths Works, Inc. 1995). The consit function in the Optimization Toolbox is used for solving the model. The constraint (67) requires special treatment as it involves the risk level $r_{l}$ that is to he evaluated through an integration given in (63). These constraints are invoked using M-File Function (The Maths Works, Inc. 1995). The risk is expressed in the M-File,using Simpson's general formula for numerical integration. As the constr function may not give the global optimum (The Maths Works, Inc. 1994), different local optima are obtained starting with differentinitial vector of decision variables. The extreme value among such local optima is chosen as the global optimum and the corresponding vector of decision variables is taken as the optimal solution.

\section{Results and discussion}

The results of the analysis are summarized in table 7 . The optimal value of the objective function is $\lambda^{*}=0.2541$, and it corresponds to the max-min satisfaction level in the system. Also shown in the table 7 is the DO deficit information at the various water quality check-points. The DO deficit values corresponding to the optimum fraction removal levels are given for the water quality check-points $12-16$ where the DO deficit is deterministic. For the checkpoints 1-11, the risks of law water quality corresponding to the optimum fraction removal levels are computed using (63). The limits of the integration in (63), namely $c_{7}^{\text {min }}$ and $c_{7}^{\operatorname{mox}}$, are computed using (61) and (62), which in turn depend on the data given in table 5 and the optimum fraction removal levels given in table 7. The PDF $f\left(c_{i}\right)$ and the membership function $\mu_{W_{l}}\left(c_{l}\right)$ in the expression for $r_{l}$ are expressed as functions of $c_{\text {l }}$ by means of (59) and (60) respectively, and then the risk $r$ is evaluated from (63) using numerical integration. The risk levels (corresponding to the optimum fraction removal levels) obtained by performing the numerical integration are given in the fourth column of table 7 , for the checkpoints 1-11. Figure 14 shows the variation in the risk of low water quality at the check-paints $1-1$ I. It may be seen that, as we proceed downstream, the risk of low water quality increases and attains a maximum value of $21.54 \%$ atthecheck-point 11 . The CDF of DO deficit at, a check-point $I$ is obtained from (58) after substi. luting the value of $B_{i}$ corresponding to the optimum fraction removal levels. As an example, figure 15 shows the CDF of DO deficit at the check-point II Similar information is obtained for other check-points a]so.

Table 7. Summary of results

\begin{tabular}{|c|c|c|c|c|}
\hline \multirow[b]{2}{*}{$\begin{array}{l}\text { Discharger } \\
D_{m}\end{array}$} & \multirow{2}{*}{$\begin{array}{c}\text { Optimum } \\
\text { fraction } \\
\text { removal level } \\
x_{m}^{*}\end{array}$} & \multicolumn{3}{|c|}{ Water quality } \\
\hline & & $\begin{array}{l}\text { River } \\
\text { reach } \\
u_{e}\end{array}$ & $\begin{array}{c}\text { Risk } r_{l} \text { of low water } \\
\text { quality at check-point } / \\
(\%)\end{array}$ & $\begin{array}{l}\text { DO deficit } c_{l} \\
\text { at check-point } \\
\left(\mathrm{mg} \mathrm{l}^{-1}\right)\end{array}$ \\
\hline$D_{1}$ & 0.6229 & $u_{1}$ & $\begin{array}{l}r_{1} \approx 0 \\
r_{2} \approx 0\end{array}$ & ND \\
\hline$D_{2}$ & 0.6857 & $u_{2}$ & $\begin{aligned} r_{3} & =0.12 \\
r_{4} & =0.24 \\
& =0.34\end{aligned}$ & ND \\
\hline$D$, & 0.7348 & $u_{3}$ & $\begin{array}{l}r_{6}=1.70 \\
r_{f}=\mathbf{1 9 9} \\
r_{s}=\mathbf{2 . 6 9}\end{array}$ & ND \\
\hline$D_{4}$ & 0.7102 & Hi & $\begin{aligned} r_{q} & =\mathbf{3 . 3 8} \\
r_{10} & =15.41 \\
r_{11} & =21.54\end{aligned}$ & ND \\
\hline$D_{5}$ & 0.6484 & $u_{5}$ & ND & $\begin{array}{l}c_{12}=0.4766 \\
c_{13}=0.7163\end{array}$ \\
\hline$D_{6}$ & 0.7475 & $u_{6}$ & ND & $\begin{array}{l}c_{14}=0.8933 \\
c_{15}=2.1823 \\
c_{16}=2.7528\end{array}$ \\
\hline
\end{tabular}

$\mathrm{ND}$, value not defined. 


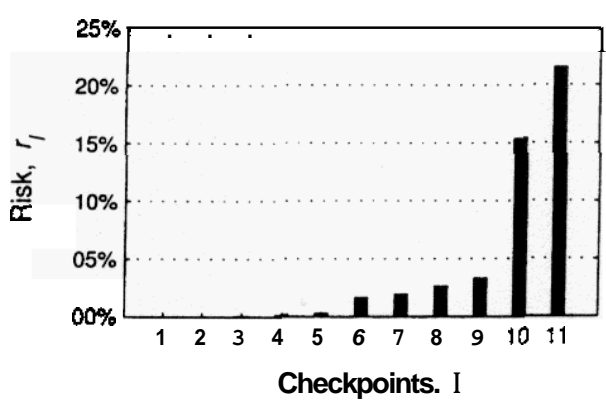

Figure 14. Variation in the risk of lox water quality.

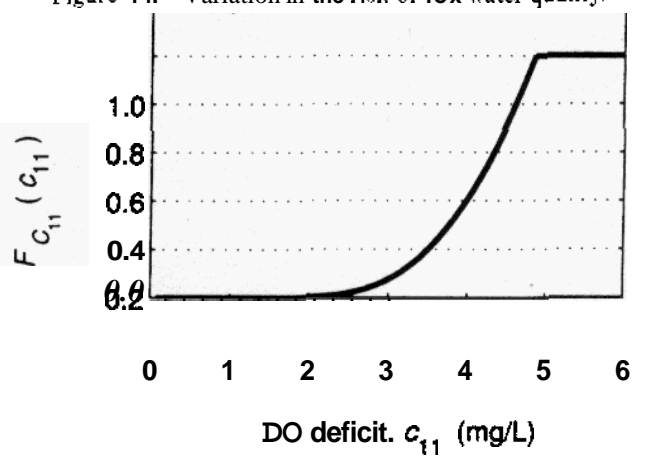

Figure 15. CDF of DO deficit at tho check-point 11 .

The fuzzy risk proposed in this study may be used as an effective measure to describe the fuzzy probabilistic aspects of the water quality indices governed by both randomness and vagueness. It may be expected that the furry risk will be greater than the risk obtained by considering only the randomness of the water quality indices. This is because the fuzzy risk considers the full range of concentration levels of the water quality indices as low water quality with varying degrees of low water quality. On the other hand. the risk obtained from only the probability consideration takes into acoount only those concentration levels which are either smaller (for water quality index $i$ whose desirable level is greater than the permissible level) or greater (for water quality index $j$ whose desirable level is less than the permissible level) than a particular concentration level and not the full range of concentration levels ass low water quality. Moreover, the pollution control agency has the flexibility to consicter a wide range of risk levels by choosing the parameters $a_{2 w l}, n_{2 w /}$ and $r_{w /}^{\mathrm{M}}$ appropriately in the membership functions for the goals $G_{1:}$ related to the risk of low water quality at the check-point $l$. For example, it may be possible for the pollution control agency to put a stringent condition on the risk level by setting a lower value for $r_{\mathrm{w} /}^{\mathrm{M}}$. A consequence of this will be an increased fraction removal level for the sischar. gers. A wide spectrum of decisions can be arrived at by choosing appropriate membership futrcions for the different fuzzy goals and the fuzzy sets of low water quality. By a mutual interaction between the pollution control agency and the dischargers, an agreement upon the various fuzzy goals and the related membership functions can he arrived at and this will help to take a best compromise decision acceptable to both the pollution control agency and the dischargers. The results obtained from the fuzzy optimization model incorfiorating the risk of low water quality described in a more realistic framework may be used in the planning and design phases of water quality management of a river systern.

\section{Conclusion}

A fuzzy waste load allocation model is developed in the present study to incorporate the uncertainties due to randomness and vagueness associated with the water quality management of a river system. Considering the two forms of uncertainty (randomness and vagueness) simultaneously, water quality management of a river system is addressed in a fuzzy probabilistic framework. The goals of the pollution control agency related to low water quality are redefined in view of the random nature of the water quality indices. For this. a fuzzy set-based definition that is a more general case of the existing crisp-set-based definition of low water quality is comsidered. The event of low water quality at a check-point in the river system is considered as a fuzzy event. The fuzzy risk of low water quality is then defined as the prohability of the fuzzy event of low water quality. Instead of constraining the risk of violation of water quality standard by is finite value of risk through a chance constraint, a fuzzy set of low risk that considers a range of risk levels with appropriate membership values is introduced. Different goals associdted with the water quality aspects of the management problem are expressed as fuzzy sels. The exponential-type membership functions used for these goals provide flexibility in expressing the aspirations appropriately with regard to the water quality. The resulting management problem is formulated as a fuzzy mulsiobjective optimization problem. The model is applied to a hypothetical river system 10 ilfustrate the furzy probabilistic modeling in the water quality management of a river system Assigning appropriate values lor the parameters of the membership functions belps the decision makers to account for the aspirations regarding the attaimment of respectuve goals. The furry aptimization model may be expected to act is an aid to decision making for water quality management of a river system 


\section{- References}

AREAB], M., and Elzinga, J., 1915. A general linear approach to stream water quality modeling. Water Resources Research, 11, $191-196$.

BELLMAN, R. E. . and ZADEH, L.A., 1970, Derision-making in a fuzzy environment. Management Science, 17, B-141-B-164.

Beran, M. A., and RoDier, J. A., 1985, Hydrological Aspects of Drought. A Comtribution to the International Hydrological Programme (Oxford UNESCO-WMO) (New Delhj: IBH Publishing), pp. 74-75.

BurN, D. H., and McBean, E. A., 1985, Optimization modeling of water qualify in an uncertain environment. Water Resources Research. 21, 934-940.

Chang, N., Chen, H. W., Shaw, D.G., and Yang, C. H., 1997 Water pollution control in river basin by interactive fuzzy interval multiobiective programming. Journal of Environmental Engisteering. 123, $1208-1216$

Chang, N. , and Wang, S. W.. 1996, Managerial fuzzy optimal plannang for solid waste management systems. Journal of Environmencol Engineering, 122, 649-658.

Elcls, I. H., 1987. Stochastic water quality optimization using imbedded chance constraints. Water Resources Research, 23, 2227 2238.

FENG, Y., 1983, A method using fuzzy mathematics to solve the vector maximum problem. Fuzzy Sets and Systems, 9, 129-116.

Fontane, D. G., Gates, T. K., and Moncada, E., 1997, Planning reservoir operations with imprecise objectives. Journal of Warer Resources Planming and Mamagemen, 123, 154- 162

Fugiwara, O., Gnanendran, S. K.. and Ohgaki, S., 1986, River quality management under stochastic streamflow. Jourmal of Environmental Engineering, 112, 185-198; 1997; Chance constrained model for tover water quality management. Journal of Environmental Engineering, 113, 1018-1031

Fugiwara, O., Puangmaha, W.. and Hanaki, K., 1988. River basin water qualify management in stochastic envirenment. Journal of Environmental Engineering, 114, 864-877.

Gromec, M. J., Loucks, O. P., and OrLob, G. T. .1983, Stream quality modeling. Mathenatical Modeling for Water Quality: Streams, Lakes and Reservoirs, edited by G. T. Orlob (Wiley IIASA Sejies, Vol. 12 (New York Wiley!. pp. 176226.

HATHHORN, W. E., m d TUNG, Y. K. .1989. Bi-objective analysis of waste load allocation using fuzzy linear programming Woier Resources Management. 1 243-257.

James, A.. and ELLIOT. D. T. . 1993. Models of water quality in rivers An Iniroduction to Waier Quality Modeling. second edition, edited by A. James (New York: Wiley). pp. 141-181.
KINDLER, J., 1992, Rationalizing water requirements with aid of fuzzy allocation model. Journal of Water Resources Planning and Management, 118, 308-323.

LiANG, R. H., and Hsu, Y. Y., 1994, Fuzzy linear programming: An application to hydroelectric generation scheduling. Proceedings of the Institution of Electrical Engineers, Pt C, 141, 568-574.

LOHANI, B. N., and Thanh, N. C., 1978, Stochastic programming model for water quantity management in a river. Journal of the Water Pollution Control Federation, 50, 2175-2182; 1979 Probilistic water quality control policies. Journal of Environmental Engineering, 105, 713-725.

OWen, W. J., Gates, T. K., and Flug, M., 1997, Variability in perceived satisfaction of reservoir management objectives. Journal of Water Resources Planning and Management, 123, 147-153.

RAO, S. S., 1987 a, Multi-objective optimization of fuzzy structural systems. International Journal of Numerical Methods in Engineering, 24, 1157-1171; 1987 b, Optimum design of structures in a fuzzy environment. AIAA Journal, 25, 1633-1636; 1993; optimization using fuzzy set theory. Structural Optimization: Status and Promise, edited by M. P. Kamat, Progress in Astronautics and Aeronautics, Vol. 150 (New York: American Institute for Aeronautics and Astronautics), pp. 637-661

Rao, S. S., Sundararaju, K., Prakash, B. G., and Balakrishna, C., 1992, Multiobjective fuzzy optimization technique for engineering design. Computers and Structures, 42, 37-44.

SAKAWA, M., 1995, Fuzzy programming. Fuzzy Systems for Management, edited by K. Asai (Bruke: IOS Press), pp. 57-78

Sasikumar, K., and Mujumdar, P. P., 1998, Fuzzy optimization model for water quality management of a river system. Journal of Water Resources Planning and Management, 124, 79-88.

The MAtH WORKs, INC., 1994, Optimization TOOLBOX for use with MATLAB: User's Guide, pp. 2-22-2-32, 3-9-3-12; 1995, The Studen edition of MATLAB: User's Guide, Version 4 (Englewood Cliffs, New Jersey: Prentice-Hall), pp. 105-106.

Thomann, R. V., and Mueller, J. A., 1987, Principles of Water Quality Modeling and Control (New York: Harper and Row), pp. 1-89, 261-384.

Yevjevich, V., 1972, Probability and Statistics in Hydrology (Fort Collins, Colorado: Water Resources Publications), pp. 156-159

ZADEH, L. A., 1965, Fuzzy Sets. Information and Control, 8, 338-353, 1968, Probability measures of fuzzy events. Journal of Mathematical Analysis and Applications, 23, 421-427.

ZimmermanN, H. J., 1978, Fuzzy programming and linear programming with several objective functions. Fuzzy Sets and Systems, 1, 45 55; 1985, Application of fuzzy set theory to mathematical programming. Information Sciences, 36, 29-58. 